\title{
Red Blood Cells Folate Level in Patients with Alopecia Areata
}

\begin{abstract}
Keywords: Alopecia areata; Folic acid; RBCs
Abstract

Background: Alopecia areata (AA) is a common type of hai loss affecting $1-2 \%$ of general population, characterized by well demarcated patches of hair loss, which can progress to a complete loss of hair from the scalp or from the whole body in severe cases. Its exact pathogenesis is still unknown, although many theories have been suggested including infectious, neural, genetic, and organ specific autoimmune hypotheses. Over the past decade, interest in the health benefits of folic acid has increased considerably as it is essential for normal cell growth and metabolism. Folic acid supplementation has been demonstrated to reduce some inflammatory mediators relevant in atherosclerosis, insulin sensitivity and other inflammatory conditions including skin diseases. The speculative role of folic acid in modifying skin inflammatory responses needs further biologic and clinical studies.

Objective: The aim of this study is to detect the role of RBCs folate in patients with alopecia areata and the relation between its level with the severity and the pattern of AA.
\end{abstract}

Subjects and methods: A case control study of 34 alopecia areata patients and 34 healthy controls was conducted. RBCs folate level was measured in cases and controls by standard enzymelinked immunosorbent assay (ELISA). Results: RBCs folate levels show a statistically significant difference between the two groups. There is no correlation between RBCs folate levels and pattern or severity of alopecia.

Conclusion: Folate deficiency may play a role in the pathogenesis of AA. Folic acid may be a reasonable and specific treatment strategy of $A A$ in the future.

\section{Introduction}

Alopecia areata is a non-scarring hair loss of the scalp, and/or body. Its pathogenesis has experienced considerable drift over the years and different schools of thought have assigned varied etiologies to the condition [1]. Until it is accepted as a chronic inflammatory autoimmune disorder, characterised by $\mathrm{T}$-cell and macrophage infiltration into the hair follicles and in the proximal epithelium of a growing hair follicle, with genetic predisposition, environmental and psychological triggers may be involved [2].

Approximately $12 \%$ of individuals with AA developed an autoimmune disease. There was an increased frequency of thyroid disorders, pernicious anemia, psoriasis, and vitiligo in patients with AA [3].

Folic acid is a water-soluble vitamin B essential for normal cell growth and metabolism and it is critically required for DNA repair processes [4]. Folate deficiency is regarded as the most common vitamin deficiency in developed countries. The prevalence and the magnitude of its deficiency across the world are unclear [5].

Methylenetetrahydrofolate reductase (MTHFR) is a key enzyme regulating folate metabolism and it is thought to influence DNA methylation and nucleic acid synthesis. MTHFR is also one of the main regulatory enzymes in the metabolism of homocysteine [6].

\section{Journal of}

\section{Clinical \& Investigative} Dermatology

\section{Abdalla H kandeel ${ }^{1}$, Shrook A Khashaba ${ }^{1}$, Abdalla M Esawy $^{1 *}$ and Nermin R Abd El- Fattah ${ }^{2}$}

${ }^{\prime}$ Department of Dermatology, Venereology and Andrology, Faculty of Medicine, Zagazig Univeristy, Zagazig, Egypt

${ }^{2}$ Department of Medical Biochemistry, Faculty of Medicine, Zagazig University, Zagazig, Egypt

\section{*Address for Correspondence}

Abdalla M Esawy, Department of Dermatology, Venereology and Andrology, Faculty of Medicine, Zagazig Univeristy, Zagazig, Egypt, E-mail: abdesawy@hotmail.com

Submission: 13 February, 2017

Accepted: 29 March, 2017

Published: 10 April, 2017

Copyright: () 2017 kandeel $\mathrm{AH}$, et al. This is an open access article distributed under the Creative Commons Attribution License, which permits unrestricted use, distribution, and reproduction in any medium, provided the original work is properly cited.

A high prevalence of methylenetetrahydrofolate reductase (MTHFR) mutations as well as increased homocysteine levels in populations with autoimmune diseases such as multiple sclerosis (MS), systemic lupus erythematosus and Graves disease (GD) indicating a potential genetic association between MTHFR and autoimmune disorders [7]. Gene alterations with DNA methylation at the MTHFR gene C677T and other genes involved with the methylation process were linked with autoimmune hair loss [8]

Folate acts directly to produce antioxidant effects and indirectly to lower homocysteine levels and insure optimal functioning of the methylation cycle. Folate metabolism provides an interesting example of gene-environmental interaction. Average serum folate concentrations were $(9.2 \mu \mathrm{g} / \mathrm{L})$ for men and $(9.8 \mu \mathrm{g} / \mathrm{L})$ for women; average red blood cell folate concentrations were $(306 \mu \mathrm{g} / \mathrm{L})$ for men and $(302 \mu \mathrm{g} / \mathrm{L})$ for women [9].

The plasma folate level is subjected to greater fluctuation as it can be impaired by exogenous factors such as drugs and diet while folate concentrations in RBCs are regarded as indicators of the longterm folate status during the past 120 days and are not affected by exogenous factors [10].

\section{Patients and Method}

The study was carried out at Outpatient clinic of Dermatology, Venereology \& Andrology Department and Biochemistry Department, Faculty of Medicine, Zagazig University Hospitals during the period from November 2015 till April 2016. This study was planned to include 68 subjects, 34 alopecia areata patients (group 1) and 34 age and sex matched healthy controls (group 2). An informed written consent was signed by all participants and the study design was approved by institutional review board (IRB) committee of faculty of Medicine, Zagazig University. History, general examination to all subjects was done to exclude associated systemic diseases that may affect RBCs folate level and dermatological examination to confirm the presence or absence of AA. 
Citation: kandeel AH, Khashaba SA, Esawy AM, El- Fattah NRA. Red Blood Cells Folate Level in Patients with Alopecia Areata. J Clin Investigat Dermatol. $2017 ; 5(1): 4$.

ISSN: $2373-1044$

Inclusion criteria: Patients with alopecia areata whatever its pattern and severity, both sexes, all ages.

Exclusion criteria: Patients who had hypertension, diabetes mellitus, hypothyroidism and chronic renal or liver disease, patients using any immunosuppressant during the last 3 months, patients with metabolic syndrome, smokers, patients with cancers, chronic infections and sleep disorders.

Clinical assessment of the degree of alopecia areata: National Alopecia Areata Foundation working committee has devised "Severity of Alopecia Tool score" (SALT score). Scalp is divided into 4 areas namely, Vertex $40 \%$ (0.4) of scalp surface area; right profile of scalp $18 \%(0.18)$ of scalp surface area; left profile of scalp 18\% (0.18) of scalp surface area; Posterior aspect of scalp 24\% (0.24) of scalp surface area. Percentage of hair loss in any of these areas is percentage hair loss related to scalp multiplied by percent surface area of the scalp in that area. SALT score is the sum of percentage of hair loss in all above mentioned areas [10]. The extent of scalp hair loss was determined by Alopecia SALT score as following: $\mathrm{S}=$ scalp hair loss, $\mathrm{S} 0=$ no hair loss, $\mathrm{S} 1=<25 \%$ hair loss, $\mathrm{S} 2=25-49 \%$ hair loss, $\mathrm{S} 3=50-74 \%$ hair loss, $\mathrm{S} 4=75-99 \%$ hair loss, $\mathrm{S} 4 \mathrm{a}=75-95 \%$ hair loss, $\mathrm{S} 4 \mathrm{~b}=96-99 \%$ hair loss, S5 $=100 \%$ hair loss.

Classifications of patients: Patients were classified regarding the severity of AA according to SALT score into: Mild AA: patients who were S1 ( $<25 \%$ hair loss), moderate AA: patients who were S2 (25$49 \%$ hair loss), severe AA: patients who were S3, S4, and S5 (>50\% hair loss). Patients were classified according to the pattern of AA into: Single patch, multiple patches, alopecia totalis, and alopecia universalis.

Measurement of RBCs folate: RBCs folate level was measured in cases and controls by standard enzyme- linked immunosorbent assay (ELISA) kit provided from WKEA MED SUPPLIES CORP Company, catalogue number 9305346.

Calculation of the results: The standard curve was done by using Convergent ELISA Reader with the standard density as the horizontal axis $(\mathrm{x})$ and the OD value as the vertical axis $(\mathrm{y})$. The concentration of the unknown test may then be estimated from the calibration curve. Assessment of RBC folate level: An erythrocyte folate level of 140 $\mu \mathrm{g} / \mathrm{L}$ or lower indicates inadequate folate status [12].

\section{Statistical Analysis}

- The collected data was computerized and statistically analyzed using SPSS program (Statistical Package for Social Science) version 18.0 .

- Qualitative data was represented as frequencies and relative percentages.

- Chi square test was used to calculate difference between qualitative variables.

- Quantitative data was expressed as mean \pm SD (Standard deviation).

- Independent T test was used to calculate difference between quantitative variables in 2 groups in normally distributed data.
- Mann Whitney test was used to calculate differences between quantitative variables in 2 groups in nonnormally distributed data.

- ANOVA F-test test was used to calculate difference between quantitative variables in more than two groups in normally distributed data.

- Pearson correlation coefficient used to calculate correlation between quantitative variables.

We consider (+) sign as indication for direct correlation i.e. increase frequency of independent lead to increase frequency of dependent \& (-) sign as indication for inverse correlation i.e. increase frequency of independent lead to decrease frequency of dependent, also we consider values near to 1 as strong correlation \& values near 0 as weak correlation.

- The significance Level for all above mentioned statistical tests done.

The threshold of significance is fixed at $5 \%$ level (P-value)

${ }^{\star} \mathrm{P}$ value of $>0.05$ indicates non-significant results.

${ }^{*} \mathrm{P}$ value of $<0.05$ indicates significant results.

\section{Results}

The demographic data of studied groups are demonstrated in Table 1 showing no statistically significant difference between the two groups regarding age and sex. There is a significant statistical difference between the studied groups regarding RBCs folate level, Table 2, RBCs folate level showed a significant decrease in patients with AA with mean \pm SD $210 \pm 53.4$ when compared with normal controls with mean \pm SD $306.85 \pm 32.78(\mathrm{P}<0.001)$. There is a significant statistical difference between the studied groups regarding RBCs folate status $(\mathrm{P}<0.001)$, RBCs folate status whether sufficient $(>300 \mu \mathrm{g} / \mathrm{L})$, insufficient $(150 \mu \mathrm{g} / \mathrm{L}-300 \mu \mathrm{g} / \mathrm{L})$ or deficient $(<150$ $\mu \mathrm{g} / \mathrm{L})$, where determined in Table 3 . On determining a relation between RBCs folate level in cases and pattern, severity of AA, family history and sex the difference was statistically insignificant, Table 4. The relation between RBCs folate level and age, duration of AA, and

Table 1: Demographic data of the two studied groups.

\begin{tabular}{|c|c|c|c|c|c|c|}
\hline Variable & \multicolumn{2}{|c|}{ Cases $(n=34)$} & \multicolumn{2}{|c|}{ Control $(n=34)$} & MW & $\mathbf{P}$ \\
\hline $\begin{array}{c}\text { Age : (year) } \\
\text { Mean } \pm \text { SD } \\
\text { Median } \\
\text { Range }\end{array}$ & \multicolumn{2}{|c|}{$\begin{array}{c}27.24 \pm 14.48 \\
28.5 \\
4-57\end{array}$} & \multicolumn{2}{|c|}{$\begin{array}{c}28.68 \pm 10.41 \\
30 \\
10-49\end{array}$} & \multirow{2}{*}{$\frac{1.14}{x^{2}}$} & \multirow{2}{*}{$\begin{array}{c}0.65 \\
\text { NS } \\
P\end{array}$} \\
\hline Variable & No & $\%$ & No & $\%$ & & \\
\hline $\begin{array}{l}\text { Sex: } \\
\text { Female } \\
\text { Male }\end{array}$ & $\begin{array}{l}13 \\
21\end{array}$ & $\begin{array}{l}38.2 \\
61.8\end{array}$ & $\begin{array}{l}15 \\
19\end{array}$ & $\begin{array}{l}44.1 \\
55.9\end{array}$ & 0.24 & $\begin{array}{c}0.62 \\
\text { NS }\end{array}$ \\
\hline
\end{tabular}

Table 2: RBCs folate level among the two studied groups.

\begin{tabular}{|l|c|c|c|c|}
\hline \multicolumn{1}{|c|}{ Variable } & $\begin{array}{c}\text { Cases } \\
(\mathbf{n = 3 4 )}\end{array}$ & $\begin{array}{c}\text { Control } \\
(\mathbf{n = 3 4 )}\end{array}$ & T & P \\
\hline $\begin{array}{l}\text { RBCs folate level } \\
(\boldsymbol{\mu g} / \mathrm{L}):\end{array}$ & $\begin{array}{c}210 \pm 53.4 \\
\begin{array}{l}\text { Mean } \pm \text { SD } \\
\text { Range }\end{array}\end{array}$ & $\begin{array}{c}306.85 \pm 32.78 \\
251-367\end{array}$ & 9.01 & $<0.001^{\text {** }}$ \\
\hline
\end{tabular}


Citation: kandeel AH, Khashaba SA, Esawy AM, El- Fattah NRA. Red Blood Cells Folate Level in Patients with Alopecia Areata. J Clin Investigat Dermatol. 2017; 5(1): 4.

ISSN: $2373-1044$

Table 3: RBCs folate status among the two studied groups.

\begin{tabular}{|c|c|c|c|c|c|c|}
\hline \multirow{2}{*}{ Variable } & \multicolumn{2}{|c|}{ Cases } & \multicolumn{2}{c|}{ Control } & \multirow{2}{*}{$\mathbf{X}^{2}$} & \multirow{2}{*}{ P } \\
\cline { 2 - 6 } & No & $\%$ & No & $\%$ & & \\
\hline RBCs folate & & & & & & \\
status: & & 0 & & & & \\
Sufficient & 0 & 88.2 & 18 & 52.9 & & \\
Insufficient & 30 & 11.8 & 16 & 47.1 & 26.26 & $<0.001^{* *}$ \\
Deficient & 4 & & 0 & 0 & & \\
& & & & & & \\
\hline
\end{tabular}

severity score was analyzed in patients included in the study with no statistical significant difference detected Table 5 .

\section{Discussion}

Alopecia Areata is an organ-specific autoimmune disease characterized by T-cell infiltrates and cytokine production around anagen-stage hair follicles [13]. Autoimmunity in AA is strongly supported by clinical observations that patients with AA are often diagnosed with one or more other autoimmune disorders such as vitiligo, lupus erythematosus and Type I diabetes. In addition, the effectiveness and efficacy of various immunosuppressive agents including cyclosporine and systemic corticosteroids also suggest an autoimmune mechanism [14]. Further, the human leukocyte antigens (HLA) have been reported to play a major role in the etiology of autoimmunity. This specific hypothesis is confirmed by the increased expression of specific HLAs in AA patients such as HLA-DR, HLA-A, HLA-B, and HLA-C, which are rarely seen in healthy individuals as well as the identification of a number of genetic risk factors within various innate and adaptive immunity gene loci [15]. Cytokines including IL- $1 \alpha$, IL- $1 \beta$ and TNF- $\alpha$ may play an important role in the pathophysiology of AA. CD8+ T cells are considered to act as the effector cells with help from CD4+ T cells [16]. Folic acid is a vitamin $\mathrm{B}$ essential for the integrity and function of DNA. Relative deficiency of folic acid may occur in conditions such as pregnancy and hyperproliferative or chronic inflammatory disorders [17]. Folate deficiency inhibits the activity of CD8+ T cells and reduces the proliferative responses of lymphocytes and natural killer cell activity; in turn, this inhibition may explain the role of folate deficiency in AA [18].

The aim of this study was to detect the role of RBCs folate in patients with alopecia areata and the relation between its level and the severity and the pattern of AA.

As regards the results of RBCs folate level measured by ELISA, the level was lower in cases $(210 \pm 53.4 \mu \mathrm{g} / \mathrm{L})$ in compare to control $(306.85 \pm 32.78 \mu \mathrm{g} / \mathrm{L})$ showing a statistically significant difference $(\mathrm{P}$ value $<0.001)$.

These results are parallel with the study made by Yousefi et al. which showed a statistically significant difference between AA patients $(n=29)$ and control group $(n=32)$ regarding RBC folate concentration $(\mathrm{P}<0.001)$ which suggested that folate deficiency may have a role in AA [19]. Another study by Kalkan et al. demonstrated an association between Methylenetetrahydrofolate reductase [MTHFR) gene C677T mutation and increased risk of AA as this enzyme is an essential enzyme in folate metabolism, an impaired folate metabolism may have led to the development of AA and impaired DNA synthesis [8]. This study was done on 136 patients of AA and 130 healthy controls.

On the contrary a study by Gonul et al. investigated serum ferritin, iron, vitamin B12, and folate levels in 43 AA patients and 36 healthy individuals showed no significant difference in AA patients from the control group [20]. Also, Ertugrul et al. ran a study on 75 cases of AA and 54 healthy controls, the study measured serum holotranscobalamine, vitamin B12, folic acid and homocysteine levels in alopecia areata patients with no significant difference in these parameters between patients and control group [21].

In these both previous studies the folate level has been measured in serum not in RBCs, serum folate may not be a true indicator of the folate status in the body as it can be impaired by exogenous factors as drugs and diet, so the both previous studies don't reflect the proper relation between folic acid and AA.

In the present study AA was classified to mild, moderate, and severe degrees according to (SALT) score. By comparing RBC folate level in the patients in relation to degree of AA, we found no statistically significant difference between RBC folate level and degree of AA.

This result doesn't met with the result of Yousefi et al. who reported a significant negative correlation between the degree of AA by (SALT) score and RBC folate level in AA patients $(\mathrm{P}=0.03)$ [19]. This may be due to limited number of patients with Alopecia totalis $(\mathrm{n}=1)$ and Alopecia universalis $(\mathrm{n}=3)$ in our study compared to his study which have 13 patients with AT and 3 patients with AU.

Finally, all of these findings points to the important role of folate in the pathogenesis of AA which may open a new channel for its treatment. Accordingly, screening patients with AA for folate deficiencies seems to be of value for the proper and accurate managment of AA patients.

\section{References}

1. Amin SS, Sachdeva S (2013) Alopecia areata: an update. JPAD 23: 209-220.

2. Paus R, Nickoloff BJ, Ito T (2005) A 'hairy' privilege. Trends Immunol 26: 32-40.

3. Xiao FL, Yang S, Liu JB, He PP, Yang J et al. (2006) The epidemiology of childhood alopecia areata in China: a study of 226 patients. Pediatr Dermatol 23: $13-18$.

4. Smith AD, Kim YI, Refsum H (2008) Is folic acid good for everyone? Am J Clin Nutr 87: 517-533.

5. McLean E, de Benoist B, Allen LH (2008) Review of the magnitude of folate and vitamin B12 deficiencies worldwide. Food Nutr Bull 29(2 Suppl): S38-S51.

6. Trabetti E (2008) Homocysteine, MTHFR gene polymorphisms, and cardiocerebrovascular risk. J Appl Genet 49: 267-282.

7. Mao R, Fan Y, Zuo L, Geng D, Meng F et al. (2010) Association study between methylenetetrahydrofolate reductase gene polymorphisms and Graves' disease. Cell Biochem Funct 28: 585-590.

8. Kalkan G, Yigit S, Karakus N, Ates O, Bozkurt N, et al. (2013) Methylenetetrahydrofolate reductase C677T mutation in patients with alopecia areata in Turkish population. Gene 530: 109-112.

9. Stanger $\mathrm{O}$ (2002) Physiology of folic acid in health and disease. Curr Drug Metab 3: 211-223.

10. Eichholzer M, Tonz O, Zimmermann R (2006) Folic acid: a public health challenge. Lancet 367: 1352-1361. 
Citation: kandeel AH, Khashaba SA, Esawy AM, El- Fattah NRA. Red Blood Cells Folate Level in Patients with Alopecia Areata. J Clin Investigat Dermatol. 2017; 5(1): 4.

\section{ISSN: 2373-1044}

11. Bhat YJ, Sajad P, Hassan I (2014) Etiopathogenesis of alopecia areata. Hair Ther Transplant 4: 123

12. Antony AC (2005) Megaloblastic anemias. In: : Hoffman R, Benz E, Silberstein L, Heslop, Weitz J, et al. (Eds). Hematology: basic principles and practice, $\left(4^{\text {th }}\right.$ edn), New York, Churchill Livingstone, pp. 533-534.

13. Wang E, McElwee KJ (2011) Etiopathogenesis of alopecia areata: why do our patients get it? Dermatol Ther 24: 337-347.

14. Petukhova L, Duvic M, Hordinsky M, Norris D, Price V, et al, (2010) Genomewide association study in alopecia areata implicates both innate and adaptive immunity. Nature 466:113-117.

15. Seetharam KA (2013) Alopecia areata: an update. Indian J Dermato Venereol Leprol 79: 563-575.
16. Aksu Cerman A, Sarikaya Solak, Kivanc Altunay I (2014) Vitamin D deficiency in alopecia areata. Br J Dermatol 170: 1299-1304.

17. Gisondi P, Fantuzzi F, Malerba M, Girolomoni G (2007) Folic acid in general medicine and dermatology. J Dermatolog Treat 18: 138-146.

18. Mansouri R, Moogooei M, Moogooei M, Razavi N, Mansorabadi AH (2016) The role of vitamin D3 and vitamin B9 (Folic acid) in immune system. Int J Epidemiol Res 3: 69-85.

19. Yousefi M, Namazi MR, Rahimi H, Younespour S, Ehsani AH, et al. (2014) Evaluation of serum homocysteine, high-sensitivity CRP, and RBC folate in patients with alopecia areata. Indian J Dermatol 59: 630.

20. Gonul M, Cakmak SK, Soylu S, Kilic A, Gul U (2009) Serum vitamin B12, folate, ferritin and iron levels in Turkish patients with alopecia areata. Indian J Dermatol Venereol Leprol 75: 552.

21. Ertugrul DT, Karadag AS, Takci Z, Bilgili SG, Ozkol HG, et al. (2012) Serum holotranscobalamine, vitamin B12, folic acid and homocysteine levels in alopecia areata patients. Cutan Ocul Toxicol 32: 1-3. 